IZA DP No. 5146

Inequality of Educational Opportunity in India:

Changes over Time and across States

M. Niaz Asadullah

Gaston Yalonetzky

August 2010 


\title{
Inequality of Educational Opportunity in India: Changes over Time and across States
}

\author{
M. Niaz Asadullah \\ University of Reading, \\ SKOPE, University of Oxford and IZA \\ Gaston Yalonetzky \\ OPHI, University of Oxford
Discussion Paper No. 5146
August 2010 \\ IZA \\ P.O. Box 7240 \\ 53072 Bonn \\ Germany \\ Phone: +49-228-3894-0 \\ Fax: +49-228-3894-180 \\ E-mail: iza@iza.org
}

Any opinions expressed here are those of the author(s) and not those of IZA. Research published in this series may include views on policy, but the institute itself takes no institutional policy positions.

The Institute for the Study of Labor (IZA) in Bonn is a local and virtual international research center and a place of communication between science, politics and business. IZA is an independent nonprofit organization supported by Deutsche Post Foundation. The center is associated with the University of Bonn and offers a stimulating research environment through its international network, workshops and conferences, data service, project support, research visits and doctoral program. IZA engages in (i) original and internationally competitive research in all fields of labor economics, (ii) development of policy concepts, and (iii) dissemination of research results and concepts to the interested public.

IZA Discussion Papers often represent preliminary work and are circulated to encourage discussion. Citation of such a paper should account for its provisional character. A revised version may be available directly from the author. 
IZA Discussion Paper No. 5146

August 2010

\section{ABSTRACT \\ Inequality of Educational Opportunity in India: Changes over Time and across States}

This paper documents the extent of inequality of educational opportunity in India spanning the period 1983-2004 using National Sample Survey (NSS) data. We build on recent developments in the literature that has operationalized concepts in the inequality of opportunity theory (including Roemer's) and construct three indices of inequality of educational opportunity using data on an adult sample. Irrespective of the index used, the state of Kerala stands out as the least unequal in terms of educational opportunities. However, even after excluding Kerala, significant inter-state divergence remains amongst the remaining states. Transition matrix analysis confirms substantial inter-temporal mobility in inequality of opportunity across Indian states. Rajasthan and Gujarat in the West and Uttar Pradesh and Bihar in the Centre experienced large-scale fall in the ranking of inequality of opportunities. However, despite being poor, Eastern states of West Bengal and Orissa made significant progress in reducing inequality of opportunity. At a region level, Southern, Northeastern and Eastern regions on average experienced upward mobility (i.e. decline in inequality of opportunity) whilst the Central region experienced downward mobility. We conclude by examining the link between progress towards equality of opportunity and poverty reduction, growth and a selection of pro-poor policies.

JEL Classification: D63, O53

Keywords: $\quad$ schooling mobility, dissimilarity index, Gini of opportunity index, overlap index

Corresponding author:

M. Niaz Asadullah

Department of Economics

Henley Business School

University of Reading

PO Box 218, Whiteknights

Reading RG6 6AA

United Kingdom

E-mail: m.asadullah@reading.ac.uk

\footnotetext{
* We are very grateful to Uma Kambhampati, Marcel Fafchamps, seminar participants at the CSAE (Oxford University) Seminar Series MT 2009 and Royal Economic Society (RES) Conference 2010 for valuable comments on an earlier draft. We would also like to thank Sabina Alkire for encouraging us to undertake this research. The usual disclaimers apply.
} 


\section{Introduction}

Between-group economic inequality is a common phenomenon in mutli-ethnic societies. Such inequalities often reflect persistent differences in the capacity of individuals from different social groups to seize market opportunities, either due to discrimination or market constraints. A society with unequal opportunities is said to be characterized by a low degree of social mobility, in that individuals' economic success/status is largely predictable in terms of family background such as caste and religion. This immobility leads to intergenerational persistence in poverty, with serious implications for the process of development. What is needed is to promote a distribution of human capital where schooling varies along with individuals' level of effort instead of family background and other characteristics for which they cannot be held responsible (Roemer, 1998).

In recent years, attempts were made to measure equality of educational opportunity in terms of schooling mobility using comparable household datasets with information on individuals' family background. Two studies - Dahan and Gaviria (2002) and Behrman, Birdsall and Székely (2001) - adopt a regression-model approach to measure schooling mobility using data on children's schooling from Latin America. Educational mobility in these studies is modelled in terms of inter-generational persistence in schooling. Similarly, Schütz, Ursprung and Wößmann (2008) use comparable data on students from the TIMSS survey and develop a regression-based index of the inequality of educational opportunity in 54 countries.

However, even if we focus exclusively on the instrumental value of education as productivity enhancer, ${ }^{1}$ intergenerational correlations serve as imperfect indices of the inequality of educational opportunity for at least two reasons. Firstly, they relate a limited set of circumstances beyond the individual's control (usually the father's or mother's value for a wellbeing outcome) to his/her wellbeing outcome. Thereby, by construction, attributing too much of welfare inequality to characteristics for which individuals should be held accountable. In the inequality of opportunity literature the idea is to account for as many circumstances beyond the individual's control as possible. ${ }^{2}$

Secondly, consider the distributions of well-being conditioned by circumstances beyond individuals' control. If their dissimilarities are deemed to contribute to inequality of opportunity

\footnotetext{
${ }^{1}$ Some normative frameworks like the capability approach of Amartya Sen and Martha Nussbaum provide also justification for focusing on educational attainment as an end in itself (in addition to its role as a mean for income generation). See for instance Sen (2001).

${ }^{2}$ For more on this "partial-circumstance problem" see Fleurbaey (2008).
} 
then intergenerational correlations are inappropriate to measure inequality of opportunity even in hypothetical societies where just one single parental attribute constitutes the set of circumstances beyond the individual's control. ${ }^{3}$ As Yalonetzky (2009b) shows, several joint distributions of parental and offspring's well-being (e.g. education) can produce the same intergenerational correlations. ${ }^{4}$ By contrast studies like Gasparini (2002), Checci and Peragine (2005), Lefranc et al. (2008), Ferreira and Gignoux (2008) and Barros et al. (2009) have developed and implemented indices of inequality of opportunity that handle multivariate sets of circumstances, which is a minimum methodological requirement for quantifying inequality of opportunity. In this study, we follow an approach similar to that of Ferreira and Gignoux (2008).

The key challenge in empirically assessing the degree of inequality of opportunity is to find data on exogenous circumstance factor for adults and their parents. The most widely referred circumstance factor is parental education. However, no nationally representative large scale datasets for India provides this information for adults (i.e. individuals for whom schooling data is not censored). In the absence of such data, our study focuses on two other commonly studied "circumstance factors", namely, gender and religion of the individual ${ }^{5}$. Using data on caste, gender and religion, the objective of this paper is to look at the interplay between social origins and gender in the determination of educational opportunity in contemporary India. The key questions that we address are: (a) Are educational opportunities in India becoming more equal? (b) Are there intra- and inter-regional disparities in educational opportunities? (c) If so, how much mobility is there over time-do states that were less equal in the past have remained so today? To explore the Indian experience of progress in equalizing educational opportunities, we use National Sample Survey (NSS) data spanning the time period 1983-2004.

We calculate three indices - a Pearson-Cramer (PC) index, an overlap index and a special Gini index - in order to measure inequality of educational opportunity across Indian states ${ }^{6}$. The PC

\footnotetext{
3 A notion of inequality of opportunity wherein distributional dissimilarities matter can be developed based on a benchmark concept of equality of opportunity whereby the latter is attained if and only if conditional distributions of well-being are identical. Such concept is one of several considered by Roemer (e.g. Roemer, 1998, 2006).

${ }^{4}$ Although the class of joint distributions yielding the same intergenerational correlations get restricted as control variables are added to the regression equation.

5 According to the 2001 population Census, Muslims account for $13 \%$ of the Indian population.

${ }^{6}$ Ferreira and Gignoux (2008) normalize between-group inequality using a conceptually appealing method devised by Elbers et al. (2008). They divide between-group inequality as measured by mean log deviation by the maximum inequality that such measurement could yield given the groups' sizes and the total sample size. However the method is computationally intensive, for it requires testing for several possible allocations of the sample across the number (and sizes) of partitions, as defined by the sizes and number of the original social groups. Notwithstanding the merits of these indices, we do not use them for two main reasons: They declare equality when the means of the group-specific distributions are equal, even if the distributions are otherwise very different, and they are applicable to continuous variables whereas this paper's educational variable is discrete.
} 
index is related to one of Roemer's definitions of equality of opportunity. It takes the value of zero if and only if conditional distributions of well-being are identical across social groups and it takes its maximum value of one if and only if there is complete, or absolute, association between social group partitions and values of the outcome. ${ }^{7}$ We also estimate a multivariate, multiplegroup version of the overlap index originally proposed by Weitzman (1970). The overlap index is also equal to zero if and only if conditional distributions are identical across groups. ${ }^{8}$ Both indices share the benchmark of perfect equality of opportunity. However while the PC index is sensitive to different group sizes, the overlap index compares "representative agents" from each and every group independently of size. Therefore, with these indices, we offer results that are consistent with both approaches to group size. In addition, we estimate Lefranc et al.'s Gini of opportunity. It is an interesting index based on a definition of inequality of opportunity different to Roemer's. It measures Gini-inequality over Sen’s welfare metric (1976) across social groups.

Because the study is based on household datasets, we can describe the trends in inequality of opportunity between states and regions. In addition, we study exchange mobility of Indian states and regions in terms of decline in inequality of educational opportunity over time. Irrespective of the index used, the state of Kerala stands out as the least unequal in terms of educational opportunities. However, even after excluding Kerala, significant inter-state divergence persists amongst the remaining states. Transition matrix analysis confirms substantial exchange mobility in inequality of opportunity across India states. Rajasthan and Gujarat in the West and Uttar Pradesh and Bihar in the Centre experienced large falls in the ranking of inequality of opportunities. However, despite being home to a large number of poor people, Eastern states of West Bengal and Orissa made significant progress in reducing inequality of opportunity whilst the situation worsened in Bihar. At a region level, Southern, North-eastern and Eastern regions experienced upward mobility in terms of decline in inequality of opportunity, whereas the Central region experienced downward mobility.

The rest of the paper is organized as follows. Section 2 sets the context by providing background information on schooling in India. Section 3 explains the methodology and the data. Section 4 discusses state rankings in terms of inequality of educational opportunity and presents some potential explanation for divergent experience across the states. Section 5 is conclusion.

\footnotetext{
${ }^{7}$ For a definition and discussion of complete and absolute association see Kendall and Stuart (1973).

8 The overlap index attains its maximum value whenever for every state of wellbeing there is at least one group that does not attain it and at least one group that does. For differences in the treatment of maximum association between the overlap index and the PC index see Yalonetzky (2010).
} 


\section{Study background}

India has made significant progress in increasing enrolment and school completion over the past decades (Kingdon, 2007). Enrolment in primary schools has increased from 19.2 million in 195051 to 113.6 million in 2001. Gross primary school enrolment is nearing 100\%. Overall enrolment of children in all stages of education in India has improved over the years. Such increase in school participation has been also associated with a significant jump in the literacy rate which rose from 18\% in 1951 to 65\% in 2001 (Dougherty and Herd, 2008).

On the one hand, the growth in enrolment has taken place in the backdrop of introduction of various centrally sponsored educational interventions. Examples of such schemes include Sarva Shiksha Abhiyan (SSA), the Non-formal Education Program (1979-90), Operation Blackboard for small rural schools (1986), Total Literacy Campaigns (1988), District Primary School Education Program (1994-2002) and more recently the mid-day meal schemes. Between 1950 and 1990, the number of schools increased more than three-fold, outpacing the growth of the school age population. School participation may have responded to these supply-side changes.

On the other hand, the growth in school participation has coincided with the era of economic reform and liberalization which also saw high rates of economic growth by historical standards. Between 1983 and 2004, rural poverty declined from $46.9 \%$ to $28.4 \%$, at a rate of one percentage point a year (Lanjouw and Murgai, 2009). Economic growth may have enabled previously poorer families to enrol children in school thereby reducing inequalities in educational opportunities. Indeed the post-reform era of the nineties has been a period of fairly rapid increase in literacy and school participation (Dougherty and Herd, 2008).

Nonetheless, substantial gaps remain in educational outcomes across gender, caste, religion and between urban and rural inhabitants (Wu, Goldschmidt, Azam and Boscardin, 2006). Altogether these explain a large part of educational inequality in India; which is not only one of the highest in the world, but it has not declined much in the last three decades (Thomas et al., 2000). Recent research using multiple rounds of nationally representative data documents the persistence of gender, caste and religion gaps in school participation and attainment. A comparison of data from 1980s with that from 2000s reveals that even the later years of (1991's) liberalization have not been accompanied by a complete closure of social gaps in schooling, an important premarket factor (Desai and Kulkarni, 2008; Asadullah, Kambhampati and Lopez-Boo, 2009). 
Overall, these trends in inequality of educational outcomes are not conclusive of a reduction in inequalities of educational opportunities. For instance, there is evidence of continued importance of other "circumstance factors" such as parental wealth and education, which is suggestive of persistent inequality in educational opportunities. Indeed, India hosts a large part of the world's out-of -school children, mostly belonging to poor households (Filmer and Pritchett, 1999).

Whilst the country has made sizable progress in bringing these children to school, there remains striking contrasts in educational achievements at the state level. To this end, considerable educational investment has been made in past decades by state governments. Examples of state sponsored schemes include Lok Jumbish and Shiksha Karmi programs in Rajasthan, Education Guarantee Scheme in Madhya Pradesh, Balyam program of Andhra Pradesh and Basic Education Program in Uttar Pradesh. Andhra Pradesh is also home to one of the largest Anganwadi systems in India which brought children from particularly poor households into schools. Whilst in some states such initiatives have led to significant growth in school enrolment, there exist large disparities in educational achievement across states in India - about two-thirds of the children who do not attend school are in five of the poorest states: Bihar, Uttar Pradesh, West Bengal, Madhya Pradesh, and Rajasthan (Dougherty and Herd, 2008). Persistence of schooling inequalities in some states raises concerns regarding the extent to which educational investment has translated into greater equality of educational opportunities. Dreze and Sen (1995) attribute existing inequality in educational achievement to variation in efforts to expand basic education in different states. If inequality in the access to education continues to restrict the benefit of (public) investment in education to children from higher social class and the majority (religious) group, educational opportunities are unlikely to equalize.

For all the above reasons, it is of policy interest to study the degree of inequality of educational opportunity across Indian states. The country's federal structure and multi-ethnic nature provides an ideal setting to investigate this issue. Yet, there is no published study for India. In the absence of a lack of a statistical measure, past research on this topic has focused on the broader question of between-group inequality. A closely related study is Deshpande (2007), who examines between-group socio-economic inequalities in India. Deshpande constructs a gendercaste adjusted HDI for Indian states. ' However, this approach is rather ad-hoc as it has no explicit link to well-established theories and concepts of inequality of opportunities.

9 The Gender-Caste Development Index (GCDI) of Deshpande is based on five variables: land ownership, education, occupation, livestock, and consumer durables. 
In this paper, we build on recent developments in the literature that has operationalized concepts in the inequality of opportunity theory (including Roemer's) and construct three indices of inequality of educational opportunity using data on an adult sample. To the best of our knowledge, this is the first study that attempts to empirically investigate the extent and correlates of equality of educational opportunity across states in India. Therefore, our study fills an important gap in the otherwise rich literature on the between-region differences in human development in India.

The personal distribution of schooling described in this paper is based on a representative sample of households drawn from two periods spanning the year when the Indian economy was formally liberalized. The two time periods of the NSS chosen mark the pre- and postliberalization era in India. This presents an interesting setting to study equality of opportunity to acquire education, an important pre-market factor. ${ }^{10}$

Market liberalization has brought important changes in the distribution of background factors that matter for schooling success. The liberalisation of the Indian economy in 1991 was followed by significant economic growth and fall in poverty. However, growth patterns in the nineties are characterised by major regional imbalances. As a matter of fact, regional disparities increased in the 1990s, with the southern and western regions doing much better than the northern and eastern regions. Broadly speaking, western and southern states (Andhra Pradesh excluded) have tended to do comparatively well. The low growth states, on the other hand, form a large contiguous region in the north and east. This is a matter of concern, since the northern and eastern regions were poorer to start with. In some of the poorer states, notably Assam and Orissa, there has been very little poverty reduction during the 90s (Deaton and Dreze, 2002). These patterns have implications for equality of educational opportunity at the state level. Therefore, we go beyond documenting the progress made in equalizing educational opportunities by additionally exploring its link with poverty reduction and economic growth in a given state.

\footnotetext{
10 There is an international literature that links inequality of opportunity to changes in broader macroeconomic conditions. For instance, Birdsall, Behrman, and Székely (1998) discuss the importance of educational opportunities in the context of market reforms in Latin America.
} 


\section{Methodology and Data}

In this section we briefly introduce the three indices used for tracking changes in inequality of opportunity of education in India from 1983 to 2004. We first present the general framework of circumstances and outcomes; and then explain the PC index, followed by the overlap index, and finally the Gini index of inequality of opportunity.

\section{General framework}

We assume that societies can be partitioned into a set of individuals' types, following Roemer (1998). Each type itself is defined by a special combination of values taken by a vector of circumstances, i.e. factors over which the individual does not exert control, like parental education, ethnicity or gender. For instance, in a society with two circumstances, gender (male or female) and parental education ("low" or "high"), type "1" individuals could be those who are male and whose parents had "low" education. By combining the different categories within each and every circumstance, four types are defined in this example.

Generally $₹$ circumstances are considered, each one partitioned into $g_{i}$ categories (for $i=1,2, \ldots q$ ), making every circumstance a vector, $V_{i}$, with gi elements. By combining all the possible values in the vectors of circumstances a vector of types is defined. Formally, types are generated by a function $f$ that transforms combinations of circumstance values into a natural number representing the ensuing type:

$$
f: V_{1} \times V_{2} \times \ldots \times V_{z} \rightarrow \mathbb{N}_{+}^{T}
$$

The ensuing vector of types, $G=\{1,2, \ldots, T\}$, has $T=\prod_{i=1}^{z} g_{i}$ elements. ${ }^{11}$ All individuals having the same set of circumstances are said to be of the same type. The absolute frequency of people in a society belonging to type $t,(t \in G)$, is denoted by $N^{t}$.

Similarly outcomes or advantages can be considered in a multidimensional way. All possible combinations of outcomes (e.g. health status with education achievement and earnings and so

\footnotetext{
${ }^{11}$ Circumstances could also be continuous, which might require discretization in practical applications.
} 
on) are in the vector $O=\{1,2, \ldots, A\}$. Assuming that there are b outcome vectors, $V_{j}$, each having $m_{j}$ elements (for $j=1,2, \ldots, \mathrm{b}$ ), then multidimensional outcomes are generated by a function $q$ that transforms combinations of individual outcomes into multidimensional outcomes:

$q: V^{1} \times V^{2} \times \ldots \times V^{b} \rightarrow \mathbb{N}_{+}^{A}$

O has $A=\prod_{j=1}^{b} m_{j}$ elements, each one representing a combination of outcomes. Each outcome is partitioned in the aforementioned $m_{j}$ elements or categories. Finally, the probability of attaining a given combination of advantages (e.g. $\alpha=\mathrm{k}$ ) conditional on being of type $\mathrm{t}$ is: $p_{k}^{t}$. The absolute frequency of people being of type t and attaining a combination $\mathrm{k}$ is $N_{k}^{t}$. We define:

$$
p_{k}^{t}=\frac{N_{k}^{t}}{\sum_{\alpha=1}^{A} N_{\alpha}^{t}}=\frac{N_{k}^{t}}{N^{t}}
$$

In the one-dimensional case the number of outcomes is $A=m_{1}$. The mean of the welfare measure over the whole population is denoted by $\mu$ while $\mu_{i}$ is the respective mean for type $i$. $G_{i}$ is the Gini coefficient for type ${ }_{i}$.

\section{The Pearson-Cramer (PC) index of inequality of opportunity}

Several definitions of inequality of opportunity use the concepts that Roemer (1998) terms as circumstances, efforts and advantages. ${ }^{12}$ The PC index used in this paper relates to a literalist definitions of Roemer (1998) whereby equality of opportunity is achieved when the conditional distributions of outcomes/advantages are equal across circumstance sets. That is, circumstances should not affect the advantage either directly or indirectly through effort or random shocks. An implication of this definition is that, under a situation of equality of opportunity, any measure of between-group inequality of outcomes (i.e. Roemer's advantages), sensitive to this definition, should yield minimum inequality (usually zero, depending on normalization). This definition is also related to Fleurbaey (2008)'s concept of circumstance equalization, whereby whenever such

${ }^{12}$ For instance, Checchi and Peragine (2005), Lefranc et al. (2008); Ferreira and Gignoux (2008), Fleurbaey (2008). 
equalization happens, distributions of well-being are independent from circumstance sets, and therefore expressible only as a function of effort. A between-group inequality index sensitive to this definition should also yield minimum inequality when circumstances are neutral.

The PC index highlights the association between types, in Roemer's terminology, and sets or values of advantages/outcomes. The index achieves its maximum value, signalling maximum inequality, whenever there is complete, or absolute, association between types and advantage. ${ }^{13}$ On the other hand the index achieves its minimum value when the conditional distributions of outcomes are all identical, i.e. homogeneous, implying that the conditioning factors are irrelevant in determining the advantages. The index therefore measures a concept of inequality of opportunity based on the degree of dissimilarity of multinomial distributions, as captured by the metric of the Pearson goodness-of-fit statistic used to test homogeneity of such distributions.

The index is based on a test of homogeneity among multinomial distributions (e.g. see Hogg and Tanis, 1997). The formula of the index is equal to the statistic of the test divided by its maximum possible value (derived by Cramer, 1946):

$$
\text { (1) } H=\frac{X^{2}}{X_{\max }^{2}}=\sum_{t=1}^{T} \sum_{\alpha=1}^{A} w^{t} \frac{\left(p_{\alpha}^{t}-p_{\alpha}^{*}\right)^{2}}{\min \{T-1, A-1\} p_{\alpha}^{*}}
$$

Where $w^{t}$ is the relative weight of the population belonging to type $t, w^{t}=\frac{N^{t}}{\sum_{k=1}^{T} N^{k}}$, and $p_{\alpha}^{*}$ is the proportion of the population attaining outcome state $\alpha$ :

$$
\text { (2) } p_{\alpha}^{*}=\sum_{t=1}^{T} p_{\alpha}^{t} \frac{N^{t}}{\sum_{t=1}^{T} N^{t}}=\frac{\sum_{t=1}^{T} N_{\alpha}^{t}}{\sum_{t=1}^{T} N^{t}}
$$

This weighted average probability (2) performs the comparison of the probabilities across the different types. The closer the respective probabilities across types then the more the weighted average probability resembles each and every of its constituting probabilities (in (2)) and therefore the closer to zero the statistic in (1) is.

13 The concepts of complete and absolute association are discussed in Kendall and Stuart (1973). 
The index fulfils several axioms including population replication invariance ${ }^{14}$ and scale invariance. ${ }^{15}$ It is equal to 0 when the distributions of the compared groups/types are identical. It takes the value of 1 when there is complete, or absolute, association between circumstances and outcomes. The exact meaning of complete, or absolute, association depends on whether there are more sets of circumstances than outcomes, or the other way around. In either case, complete, or absolute, association requires that for every possible outcome there is at least one type that attains it and at least one type that does not attain it. ${ }^{16}$

The PC index is also sensitive to the migration, within a type, of an individual from one outcome state to another one. If such migration renders the departing state homogeneous (across types) and the receiving state homogeneous then the index decreases its value (i.e. moves toward less inequality). A reversal of such migration increases the index's value. ${ }^{17}$

\section{The overlap index}

The overlap index was developed by Weitzman (1970) to measure between-group inequality of income distributions. Its original formulation, for two groups and continuous variables, was:

(3) $O V_{W}=\int_{y_{\min }}^{y_{\max }} \min \{f(y) ; g(y)\} d y$,

where $y$ is a continuous variable (e.g. income) with support between a minimum and a maximum value $\left(y_{\min }\right.$ and $\left.y_{\max }\right)$ and $f$ and $g$ are density functions for two different groups. We use a different version of (3), for discrete variables, $T$ groups and a slightly different normalization that facilitates comparison with other indices:

(4) $O V_{M}=1-\sum_{\alpha=1}^{A} \min \left\{p_{\alpha}^{1} ; p_{\alpha}^{2} ; \ldots ; p_{\alpha}^{T}\right\}$,

\footnotetext{
${ }^{14}$ That is, if every individual in society is replicated $n$ times, the value of the index remains unaltered.

15 That is, if the measurements of outcomes are altered proportionately (or additively) in the same way as the boundaries of the partitions of outcomes are altered (i.e. the boundaries that determine whether for one individual $\alpha=k$ ), then the index's value remains unaffected.

${ }_{16}$ This requirement is necessary for all forms of maximum association but only sufficient, in the context of the PC index, when T>A. See Yalonetzky (2009a).

${ }^{17}$ See Yalonetzky (2009a).
} 
The overlap index (4) takes the value of zero if and only if the T distributions are identical, thus declaring equality only under circumstance neutralization, or when Roemer's literalist definition of equality holds. The overlap index also takes a maximum value of 1 whenever there is complete, or absolute, association between types and outcomes, but in the case of the overlap index a necessary and sufficient condition to achieve its maximum is: $\forall \alpha \in O, \exists\left(p_{\alpha}^{i}, p_{\alpha}^{j}\right) \mid p_{\alpha}^{i}=0 \wedge p_{\alpha}^{j}>0$. The overlap index also decreases in value when a migration, within a type, from one outcome state to another, renders both departing and receiving states' probabilities homogeneous.

The overlap index fulfils axioms of population replication invariance and scale invariance; however a key difference with the PC index is that the latter is sensitive to the relative sizes of types in the population. Therefore the PC index fulfils total population replication invariance but not an axiom of subpopulation replication invariance whereby only a part of the population is replicated without affecting the value of the index. By contrast, such axiom is fulfilled by the overlap index since it is not sensitive to the distribution of types within the population. By computing both indices we offer estimations of inequality of opportunity considering both alternatives in accounting for the distribution of types. ${ }^{18}$

\section{The Gini index of inequality of opportunity (GIO)}

Lefranc et al. (2008) propose an alternative definition of equality of opportunity. Guided by concerns over differential returns and risk of the outcome for different types of people, in the definition of Lefranc et al. (2008) circumstances may affect advantages differentially. Yet equality of opportunity is still deemed to exist as long as individuals can not rank any circumstance sets according to second-order stochastic dominance among their respective outcome distributions.

In their definition of equality of opportunity people may find some types more appealing than others in terms of the properties of their advantage lotteries (e.g. average return and risk). If people chose their circumstance before being born on the grounds of those properties (formally using a second-order stochastic dominance criterion), and if they happened to be indifferent between circumstance sets, based on that criterion, then their society is deemed to be opportunity equal.

18 The PC index and the overlap index also differ in their sensitivity to migrations in general. For a discussion see Yalonetzky (2010). 
In their framework second-order stochastic dominance helps to ascertain equality of opportunity but it is not useful to rank societies in terms of their degree of inequality of opportunity, i.e. their level of departure from perfect equality. Therefore they propose the Gini index of inequality of opportunity (GIO), which is related to Sen's welfare metric: $W(x)=\mu(x)[1-I(x)]$, where the mean of the variable $x$ is multiplied by one minus an inequality index applied to the distribution of $x$. Such metric is related to second-order stochastic dominance in that whenever society $A$ second-order stochastically dominates society $\mathrm{B}$, then, $W^{A}(x)>W^{B}(x)$. (However, the opposite is not true). The GIO of Lefranc et al. is based on Sen's metric and is defined as:

(5) $G I O=\frac{1}{2 \mu} \sum_{i=1}^{T} \sum_{j=1}^{T} w_{i} w_{j}\left|\mu_{i}\left(1-G_{i}\right)-\mu_{j}\left(1-G_{j}\right)\right|$

Whenever a society is opportunity-equal according to circumstance neutralization, or Roemer's literalist definition of equality: $\mathrm{GIO}=0$. However the reverse is not true. $\mathrm{GIO}$ may be zero even when distributions of the advantage/outcome are not equal. In such case heterogeneity in the two distributions of the advantage leads to inequality according to Roemer's literalist definition and the circumstance neutralization criterion, yet $\mathrm{GIO}=0$ implies equality of opportunity according to Lefranc et al.

\section{Data}

The data used come from the NSS 1983 and 2004 rounds. Our analysis is based on individual's school completion. ${ }^{19}$ Since these data are censored for children, we restrict our analysis to adults aged at least 25 years old. The indices relate data on school completion to a variety of circumstances such as religion and gender. ${ }^{20}$ Because for certain states, sample size was too small, we further restricted our data to 25 states $^{21}$. This yields a total of four comparable circumstance sets: Hindu male, Hindu female, non-Hindu male, non-Hindu female. For some of the analyses we also compute inequality of opportunity allowing states to differ in their circumstance sets.

${ }^{19}$ NSS defines schooling in categories: not literate -01, literate without formal schooling: EGS/ NFEC/ AEC -02, TLC -03 , others -04 ; literate: below primary -05 , primary -06 , middle -07 , secondary -08 , higher secondary -10 , diploma/certificate course -11 , graduate -12 , postgraduate and above -13 .

${ }^{20}$ As pointed out earlier, parental educational and socioeconomic background are not used because of missing data for the parents of adult heads and spouses.

21 Between 1983 and 2004, some of these states split into two parts rendering data from the two rounds incomparable. For instance, in the 2004 round Uttar Pradesh was already split into Uttar Pradesh and Uttarkhand. We have adjusted the 2004 round by treating Uttar Pradesh and Uttarkhand as one category. 
The latter include gender, religious affiliation (e.g. Hindu, Muslim, Sikh, Christian, etc.) and belonging to scheduled tribes or to scheduled castes. ${ }^{22}$

\section{Results}

Appendix Figure 1 reports the indices for the whole India over adults 25 years or older. In all cases, the point estimates are surrounded by narrow confidence intervals as is to be expected from the large sample size. This confirms the statistically significant difference of our estimates of Inequality of opportunity indices from 1983 to 2004. The plot of the PC index suggests a modest decline in inequality of opportunity whilst the opposite is true for estimate of GIO index.

National averages of the PC index and the GIO index can mask important between-state differences in educational opportunities. This is confirmed by Table 1 which reports rankings of states according to inequality of opportunity indices. Also reported is the fraction of population with primary and secondary education. Several patterns are noteworthy from the Table.

First: In the case of primary and secondary education, significant progress has been made between 1983 and 2004. In 1983, none of the states (except Delhi and Nagaland) had more than $20 \%$ of the population with up to or above secondary level education. By 2004, this increased by 2-3 folds in all states except Andhra Pradesh, Rajasthan, Orissa and Tripura. Because of the low base, the fraction of population with secondary education increased by more than $100 \%$ in the Northern state of Uttar Pradesh as well as in the Southern state of Kerala.

Similarly, the fraction of population with primary education almost doubled in almost all states between 1983 and 2004. Once again Northern states such as Uttar Pradesh and Bihar saw 100\% increases in the percentage of primary educated population. States that had invested heavily in primary education in the past (such as Kerala, Karnataka and West Bengal) also saw modest growth in primary educated population.

Second: There is some disagreement between the GIO and PC indices over the ranking of states in 1983, less so between the other two possible comparisons. However, the three indices pairwise correlate highly for 2004 data (with rank correlation coefficient values ranging from 0.76 to 0.95). Moreover, the Friedman test of rank independence strongly rejects in both years the null

22 The definitions of groups for every state are available from the authors upon request. 
hypothesis that the three rankings are independent from each other. ${ }^{23}$ The differences on the indices between the two years are statistically significant, which is reasonable considering the sample size. However the difference may not be large enough to be economically significant. In addition, the opposing trends espoused by the indices, for some states and at regional and national levels, are possible since they do not measure the same concept of inequality of opportunity. The PC and the overlap indices measure inequality as distances across multinomial distributions, which in turn are related to the degree of association between population groups (or Roemer's types) and outcomes. By contrast the GIO is a Gini index of Sen's metrics, $W(x)$, for each group in which $I(x)$ is estimated using the intra-group Gini coefficient.

Third: In 2004, there is also a negative link between level of educational attainment in the population (i.e. mean school primary/secondary completion) and inequality of opportunity. For instance, in that year, $76 \%$ of the population completed primary schooling in the least unequal state of Kerala whilst the figure for Uttar Pradesh, the most unequal state, was $44 \%$. The rank correlation coefficients reported at the right bottom of Table 1 are always positive highlighting the fact that increases in primary and secondary education, by 2004, were accompanied by reductions in inequality of opportunity across states. However, the correlations are far from perfect and seldom significant at 5\% level.

\footnotetext{
23 The statistic is asymptotically distributed chi-square with 1 degree of freedom. With values of 52.38 for 1983 and 63.52 for 2004, the null hypothesis is rejected with $99 \%$ of confidence. For more details on the Friedman test see Friedman (1937).
} 
Table 1: Estimates of Inequality of educational opportunity indices by state and year (common types)

\begin{tabular}{|c|c|c|c|c|c|c|c|c|c|c|}
\hline \multirow{3}{*}{ State } & \multicolumn{5}{|c|}{1983} & \multicolumn{5}{|c|}{2004} \\
\hline & \multicolumn{3}{|c|}{ Inequality of opportunity index } & \multirow{2}{*}{$\begin{array}{l}\% \text { of population } \\
\text { with secondary+ } \\
\text { education }\end{array}$} & \multirow{2}{*}{$\begin{array}{l}\% \text { of population } \\
\text { with primary+ } \\
\text { education }\end{array}$} & \multicolumn{3}{|c|}{ Inequality of opportunity index } & \multirow{2}{*}{$\begin{array}{l}\% \text { of population with } \\
\text { secondary+ education }\end{array}$} & \multirow{2}{*}{$\begin{array}{lr}\% \text { of } & \text { population } \\
\text { with } & \text { primary+ } \\
\text { education } & \\
\end{array}$} \\
\hline & PC & Overlap & GIO & & & PC & Overlap & GIO & & \\
\hline Andhra Pradesh & 18 & 10 & 18 & 0.09 & 0.25 & 13 & 22 & 18 & 0.18 & 0.38 \\
\hline Assam & 12 & 6 & 7 & 0.09 & 0.36 & 9 & 12 & 10 & 0.22 & 0.58 \\
\hline Bihar & 9 & 17 & 19 & 0.07 & 0.21 & 3 & 7 & 4 & 0.21 & 0.40 \\
\hline Gujarat & 23 & 15 & 12 & 0.13 & 0.33 & 10 & 13 & 9 & 0.27 & 0.56 \\
\hline Haryana & 14 & 22 & 14 & 0.12 & 0.28 & 8 & 8 & 8 & 0.27 & 0.51 \\
\hline Himachal Pradesh & 21 & 20 & 21 & 0.11 & 0.28 & 16 & 14 & 16 & 0.28 & 0.55 \\
\hline Jammu and Kashmir & 2 & 5 & 9 & 0.10 & 0.22 & 5 & 1 & 2 & 0.23 & 0.47 \\
\hline Karnataka & 20 & 18 & 15 & 0.12 & 0.34 & 14 & 20 & 14 & 0.25 & 0.50 \\
\hline Kerala & 25 & 25 & 22 & 0.13 & 0.56 & 25 & 25 & 25 & 0.30 & 0.76 \\
\hline Madhya Pradesh & 6 & 1 & 13 & 0.08 & 0.24 & 7 & 6 & 6 & 0.21 & 0.43 \\
\hline Maharashtra & 13 & 16 & 6 & 0.16 & 0.42 & 15 & 24 & 12 & 0.31 & 0.62 \\
\hline Manipur & 3 & 7 & 2 & 0.12 & 0.32 & 4 & 4 & 5 & 0.30 & 0.61 \\
\hline Meghalaya & 19 & 11 & 17 & 0.14 & 0.43 & 24 & 15 & 24 & 0.24 & 0.61 \\
\hline Nagaland & 8 & 24 & 24 & 0.21 & 0.81 & 20 & 11 & 23 & 0.35 & 0.72 \\
\hline Orissa & 4 & 9 & 16 & 0.06 & 0.22 & 18 & 18 & 19 & 0.18 & 0.42 \\
\hline Punjab & 22 & 12 & 10 & 0.15 & 0.35 & 23 & 21 & 20 & 0.33 & 0.57 \\
\hline Rajasthan & 17 & 23 & 25 & 0.07 & 0.19 & 1 & 5 & 7 & 0.15 & 0.34 \\
\hline Sikkim & 11 & 14 & 23 & 0.11 & 0.23 & 22 & 23 & 22 & 0.20 & 0.46 \\
\hline Tamil Nadu & 10 & 8 & 4 & 0.11 & 0.38 & 17 & 17 & 13 & 0.26 & 0.57 \\
\hline Tripura & 7 & 2 & 5 & 0.14 & 0.41 & 21 & 9 & 21 & 0.19 & 0.51 \\
\hline Uttar Pradesh & 15 & 21 & 20 & 0.09 & 0.22 & 2 & 2 & 1 & 0.22 & 0.44 \\
\hline West Bengal & 5 & 3 & 3 & 0.15 & 0.42 & 11 & 10 & 11 & 0.22 & 0.54 \\
\hline Arunachal Pradesh & 16 & 13 & 8 & 0.13 & 0.36 & 6 & 3 & 3 & 0.21 & 0.45 \\
\hline Delhi & 24 & 19 & 11 & 0.40 & 0.62 & 19 & 19 & 17 & 0.51 & 0.74 \\
\hline Goa & 1 & 4 & 1 & 0.17 & 0.44 & 12 & 16 & 15 & 0.42 & 0.71 \\
\hline \multicolumn{11}{|l|}{ Rank correlations } \\
\hline PC index & -- & $\begin{array}{l}0.63 \\
(.00)\end{array}$ & $\begin{array}{l}0.43 \\
(.03)\end{array}$ & $\begin{array}{l}0.16 \\
(.44)\end{array}$ & $\begin{array}{l}0.16 \\
(.42)\end{array}$ & -- & $\begin{array}{l}0.77 \\
(.00)\end{array}$ & $\begin{array}{l}0.95 \\
(.00)\end{array}$ & $\begin{array}{l}0.30 \\
(.13)\end{array}$ & $\begin{array}{l}0.51 \\
(.00)\end{array}$ \\
\hline Overlap index & $\begin{array}{l}0.63 \\
(.00)\end{array}$ & -- & $\begin{array}{l}0.71 \\
(.00)\end{array}$ & $\begin{array}{l}0.06 \\
(.79)\end{array}$ & $\begin{array}{l}-0.01 \\
(0.97)\end{array}$ & $\begin{array}{l}0.77 \\
(.00)\end{array}$ & -- & $\begin{array}{l}0.76 \\
(.00)\end{array}$ & $\begin{array}{l}0.28 \\
(.17)\end{array}$ & $\begin{array}{l}0.38 \\
(.06)\end{array}$ \\
\hline GIO index & $\begin{array}{l}0.43 \\
(.03)\end{array}$ & $\begin{array}{l}0.71 \\
(.00)\end{array}$ & -- & $\begin{array}{c}-0.36 \\
(.08)\end{array}$ & $\begin{array}{l}-0.35 \\
(.07)\end{array}$ & $\begin{array}{l}0.95 \\
(.00)\end{array}$ & $\begin{array}{l}0.76 \\
(.00)\end{array}$ & -- & $\begin{array}{l}0.43 \\
(.32)\end{array}$ & $\begin{array}{l}0.20 \\
(.02)\end{array}$ \\
\hline
\end{tabular}

Notes: (a) Figures on indices are ranks. (b) Ranks: $1=$ most unequal; 25= least unequal. (c) p-values in parenthesis. 
Fourth: The pace of improvement in inequality of opportunity has been quite uneven between states within India. To highlight the extent and direction of movement of states in terms of inequality of opportunity, we plot state ranks in Figure 1. The Y-axis corresponds to position in 1983 whilst the X-axis indicates position in 2004. If a state is above and further from the 45 degree line, it indicates increasing inequality of opportunity. Reassuringly, irrespective of the index used, Uttar Pradesh and Bihar are located above the 45 degree line and experienced significant decline in their original rank in 1983.

Fifth: Both the PC and GIO indices are sensitive to different group sizes. In order to consider an alternative assessment insensitive to group sizes, Table 1 reports estimates of overlap index, comparing "representative agents" from each and every group. Reassuringly, our key conclusions regarding changes in inequality of opportunity do not change when we use the overlap index. The index ranks Kerala as the most equal and notes large gains for West Bengal and Orissa during 1983 and 2004. Estimates for Uttar Pradesh, Bihar and Rajasthan on the other hand show significant deterioration in ranking. This remarkable similarity in results is also confirmed by high positive association between rank estimates obtained from overlap and the other two (i.e. Gini and PC) indices. Therefore, our discussion in the remaining part of the paper is largely based on estimates of GIO and PC indices. For comparability purposes, we continue reporting the overlap index. 
Figure 1: Scatter plot of ranking of states by GIO index and PC index, 1983-2004

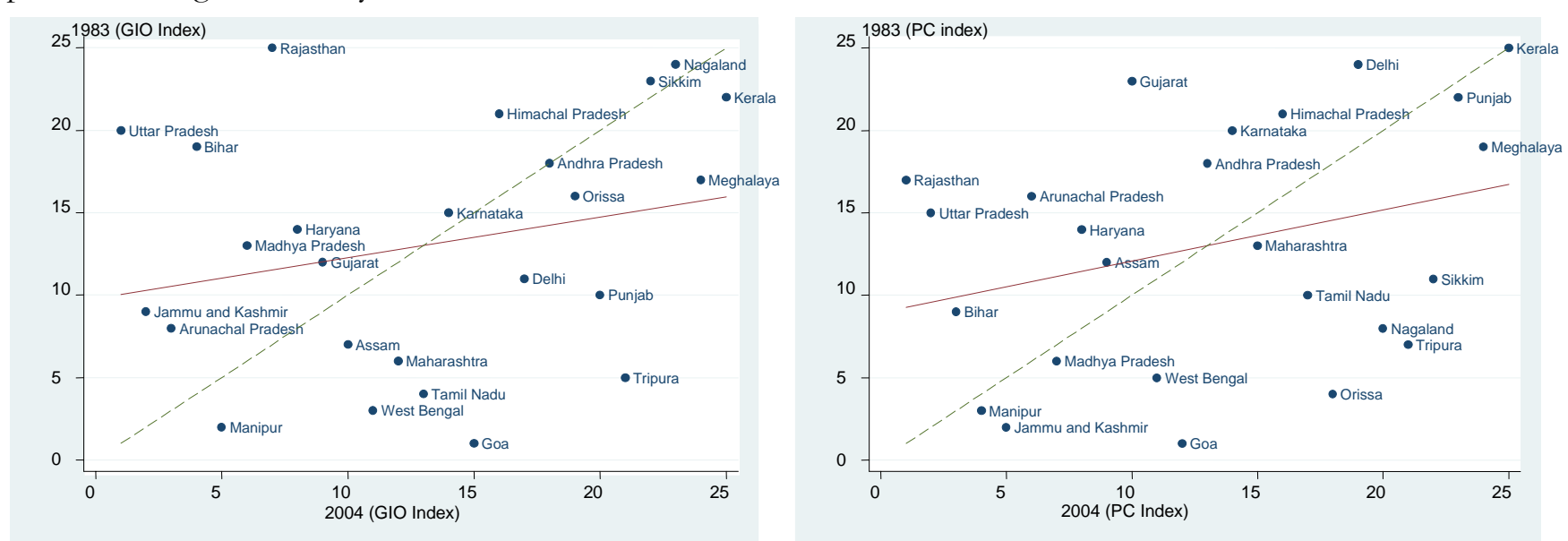

Notes: (a) Dashed line is the 45 degree line. (b) The solid line represents the linear regression trend. (c) Ranks: $1=$ most unequal; $25=$ least unequal.

Figure 2: Scatter plot of ranking of states across regions by GIO index and PC index, 1983-2004

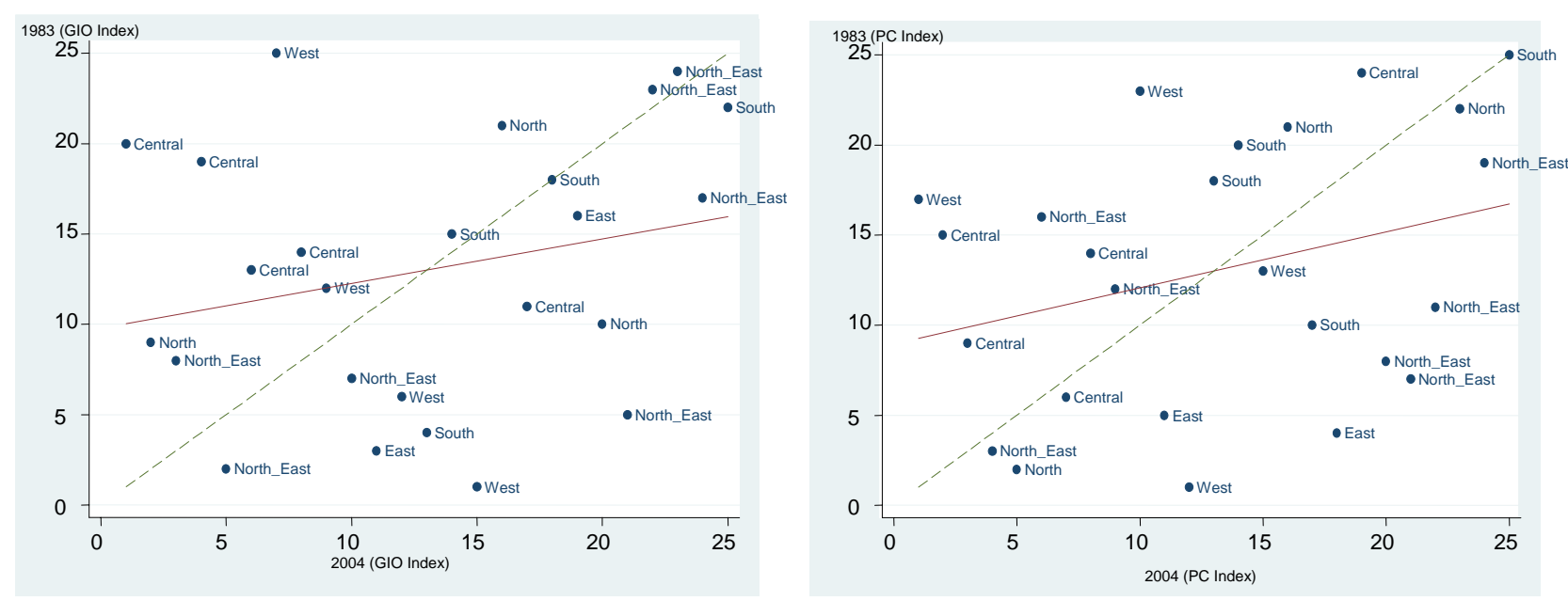

Notes: (a) Dashed line is the 45 degree line. (b) The solid line represents the linear regression trend. c) Ranks: $1=$ most unequal; $25=$ least unequal. 
To examine movement in inequality of opportunity rankings more formally, we construct a transition (quartile) matrix of the PC index for 25 Indian states (see Appendix Table 1). The calculated value of the underlying immobility indices, as measured by the trace index ${ }^{24}$ is close to unity (i.e. 0.91) implying substantial mobility in inequality of opportunity across India states. A problem in transition matrix analysis is that with only 25 observations, some cells have no observations at all. To partially circumvent the problem, we disaggregate state data by rural and urban areas and re-calculate the transition matrices using the resultant dataset which now contains 45 observations in total (see Appendix Table 2). Once again, the calculated value of the trace index remains high (i.e. 0.87 ) confirming that several states changed ranks so that many of those with relatively high inequality of opportunities in 1983 are not in the same (relative) category by $2004 .^{25}$

To what extent are observed inter-state differences in inequality of opportunity mirroring between-region inequality in educational opportunity? To answer this question, we re-produce the scatter-plot of state rankings showing the region of each state in the plot (see Figure 2). We find that:

- Western states were equally divided above and below the 45 degree line-Rajasthan and Gujarat saw a worsening of equality of opportunity whilst Maharashtra and Goa an improvement.

- Eastern states (West Bengal and Orissa) rank consistently amongst states that have succeeded in reducing inequality of opportunity.

- Southern states (Andhra Pradesh, Karnataka, Kerala, Tamil Nadu) all gained in terms of ranks (when assessed using the GIO index). However, when assessed in terms of the PC index, 2 states (Kerala and Andhra Pradesh) fell below the 45 degree line but both remained very close to the line.

- North/North-Eastern states have equal share above and below the 45 degree line

- Central (Bihar, Uttar Pradesh, Haryana) states are mostly above the 45 degree line (irrespective of the index used).

\footnotetext{
${ }^{24}$ The trace index uses the information on the diagonal of the transition matrix: $[\mathbf{n}$ - trace of $\mathbf{M}] /[\mathbf{n}-1]$ where, $M$ is the transition matrix and $\mathrm{n}$ is the number of rows/columns.

${ }^{25}$ With more observations, the Pearson chi-square statistic is now significant (p-value of 0.05 against 0.20 in Appendix Table 2).
} 
Appendix Table 3 reports overall ranks of various Indian regions. Once again, to examine how much mobility there is across regions, we compute quartile transition matrix and immobility indices (see Appendix Table 4). Given only 6 regions in India, we further disaggregated the data by rural/urban location of the households to enlarge the sample size. The value of trace index is once again close to unity (i.e. 0.87 ) implying substantial mobility in inequality of opportunity across India regions. The Pearson chi-square statistic however is only marginally significant (pvalue 0.11 ) which likely owes to the small number observations.

To better understand the movements in the position of regions across the distribution of inequality of opportunity, we plot region-specific values of the PC and GIO indices in Appendix Figure 2 by year. It is easy to trace changes in inequality of opportunity in education across Indian regions using the graphs. Several patterns are noteworthy: (a) irrespective of the index used, the central region saw a rise in inequality of opportunities; (b) irrespective of the index used, the southern, eastern and north-eastern regions saw a decrease in inequality of opportunities; (c) compared to the GIO index, there is more movements across regions in terms of the PC index.

Lastly, our preceding analysis only allowed for similar types across states. In Appendix Table 5 we allow states to differ by types' composition. The positive correlation between educational attainment and equality of opportunity in 2004 is robust to this change in type definitions. On the other hand, whilst all the three indices remain significantly correlated, the correlation is far from perfect highlighting the fact that they measure different aspect of the notion of inequality of opportunity.

\section{Policy origin of inequality of opportunity}

What can explain the large-scale fall in the ranking of Rajasthan and Gujarat in the West and Uttar Pradesh and Bihar in the Centre? On the other hand, what explanation is there for reductions in inequality of opportunity in the Eastern states of Orissa and West Bengal that are much poorer? These questions are interesting because in the last two decades, India has experienced significant economic growth at a sustained rate. The 1990s saw significant fall in poverty, a significant source of disadvantage for children born into Muslim and other minority social groups (e.g. scheduled caste, scheduled tribe). Overbearing poverty has been a significant cause of withdrawal of children from schools. GDP growth and poverty reduction has been 
achieved in the backdrop of 1990s market liberalization which has also led to changes in economic structure and organization. These changes may have relaxed household credit constraints and altered household returns to investment in education. However, gains in poverty reduction following economic growth have not been equally divided across states.

In a federal state like India, provision of public goods is the responsibility of individual states. The importance of state-level policy choice is well documented in the literature. In a seminal study, Dreze and Sen (1995) demonstrate how differences in entitlement to basic services between Uttar Pradesh and Kerala are related to differences in the scope and quality of public services such as school facilities which in Uttar Pradesh are often non-existent. Relevant factors, among others, are the importance of social movements and public action, and the lack of political power of socially disadvantaged groups (or agency of scheduled tribe/scheduled caste/Muslim population).

In the above setting, between-state differences in policies and institutions can lead to differences in inequality of educational opportunity for a number of reasons. First, certain states in India display a poor record in terms of gender gaps in the labour market which can distort household investment decisions in female schooling. For instance, the northern Indian state of Uttar Pradesh has a long history of oppressive gender relations. Other states such as Punjab and Haryana have some of the lowest sex ratios. On the other hand, women's economic participation has been active in the Southern state of Kerala for a long time, which is arguably responsible for a wide range of social achievements. Kerala and Tamil Nadu also have high sex ratios. Second, there is significant difference in access to public infrastructure by various social groups in India. According to the Sachar Commission report 2006, Muslims in India are frequently found in relatively unbanked villages, and access to credit matters for human capital acquisition. Therefore, differences in financial provisions across states can influence educational attainment by gender and religious membership. Third, Indian states differ in terms of overall spending on education as well as educational policies/interventions. Higher spending per se may not be enough to equalize opportunities. Some states have policies targeting disadvantaged and/or difficult-to-reach social groups. These states can be expected to succeed in equalizing educational opportunities. Lastly, more accountable states may have affirmative action policies that attenuate the adverse effect of discriminatory factors such as caste and religion. For all these reasons, it is of policy interest to document why inequality of educational opportunity varies across Indian states. 
We go beyond documenting state-rankings in inequality of opportunity by examining the reasons for the divergence in state-level experience of equalizing educational opportunities. In order to delve a little deeper into the state-level policy factors and experiences with economic growth and poverty reduction, we build on Besley et al. (2007). Table 2 connects the policy analysis above to the earlier discussion of the link between economic growth and educational opportunity. It ranks 16 Indian states by percentage change in inequality of opportunity and their growth elasticity of poverty, GDP growth rates, rates of poverty reduction, and performance in four areas of policy discussed above: voice and accountability; access to finance; human capital investment and gender inclusion. All variables relating to economic growth, poverty and policies are in lagged form.

The table thus allows an informal look at how policy performance such as gains in GDP growth and poverty reduction are linked to the changes in inequality of educational opportunity. The first three columns in Table 2 present rankings in terms of percentage changes in inequality of opportunity indices. The next column ranks the states in terms of economic growth and poverty reduction. These states have tended to have fast growth rates and high growth elasticities of poverty (rankings are in columns 5 and 6 respectively). Poverty reduction is greatest in states like Kerala, Punjab, and Andhra Pradesh (states with significant reduction of inequality of educational opportunity) whilst it is lowest in states like Bihar, Assam, and Madhya Pradesh (states with poor record of equality of educational opportunity).

On the whole, there is a statistically significant, positive correlation (rank correlation coefficients of $0.49-0.64)$ between inequality of opportunity and poverty reduction. States that have been more successful in reducing poverty are also those who have been more successful at reducing inequality of opportunity between 1983 and 2004. Similar positive correlations also exist with respect to GDP growth rate and growth elasticity of poverty. However, the rank correlation coefficients are smaller in size suggesting the relative importance of poverty reduction over the other two variables in equalizing educational opportunity.

The remaining columns correlate inequality of opportunity indices with four selected policy indicators. In the column on voice and accountability, a higher newspaper circulation per capita is associated with a higher growth elasticity of poverty, a higher growth rate, a higher overall 
reduction in poverty and a higher percentage reduction in inequality of opportunity. ${ }^{26} \mathrm{~A}$ similar pattern is found in the access to finance column, where states are ranked by per capita credit extended by commercial banks. States with greater access to finance have higher ranks in all three indices (although not statistically significant for the PC index). The pattern of correlations between human capital, proxied by state education expenditures per capita, and changes in inequality of opportunity is recorded in the next column. The correlation of this variable with changes in inequality of opportunity indices is insignificant, and not always positive. In other words, states that have spent more on education are not always successful in reducing inequality of opportunity. Finally, in the column on gender, inclusion of women in the labour force, as proxied by the ratio of female-to-male workers, is positively correlated with changes in inequality of opportunity rankings irrespective of the index used.

${ }^{26}$ Only the rank correlation of the voice and accountability indicator with the PC index is not statistically significant. 
Table 2: Inequality of opportunity rankings vis-à-vis growth, poverty and policies of Indian states (common types)

\begin{tabular}{|c|c|c|c|c|c|c|c|c|c|c|}
\hline \multirow[b]{2}{*}{ State } & \multicolumn{3}{|c|}{$\begin{array}{c}\% \text { change in Inequality of } \\
\text { opportunity index }\end{array}$} & \multicolumn{3}{|c|}{ Progress in growth and poverty } & \multicolumn{4}{|c|}{ Pro-poor policies } \\
\hline & PC & Overlap & GIO & $\begin{array}{l}\text { Poverty } \\
\text { reduction }\end{array}$ & $\begin{array}{l}\text { Growth } \\
\text { rate }\end{array}$ & $\begin{array}{l}\text { Growth } \\
\text { elasticity } \\
\text { of poverty }\end{array}$ & $\begin{array}{l}\text { Voice and } \\
\text { accountability }\end{array}$ & $\begin{array}{l}\text { Access to } \\
\text { Finance }\end{array}$ & $\begin{array}{l}\text { Human } \\
\text { capital } \\
\text { investment }\end{array}$ & $\begin{array}{l}\text { Gender } \\
\text { (female- } \\
\text { male } \\
\text { workers) }\end{array}$ \\
\hline Andhra Pradesh & 9 & 3 & 9 & 4 & 5 & 4 & 10 & 9 & 12 & 4 \\
\hline Assam & 7 & 9 & 6 & 16 & 10 & 14 & 15 & 15 & 4 & 2 \\
\hline Bihar & 14 & 13 & 14 & 14 & 16 & 15 & 14 & 16 & 15 & 12 \\
\hline Gujarat & 13 & 12 & 10 & 6 & 6 & 6 & 6 & 6 & 7 & 8 \\
\hline Haryana & 12 & 14 & 12 & 9 & 1 & 9 & 13 & 7 & 2 & 14 \\
\hline Jammu and Kashmir & 8 & 11 & 13 & 15 & 13 & 9 & 11 & 10 & 1 & 16 \\
\hline Karnataka & 10 & 10 & 8 & 8 & 8 & 10 & 7 & 5 & 8 & 3 \\
\hline Kerala & 1 & 4 & 1 & 1 & 7 & 1 & 1 & 8 & 5 & 1 \\
\hline Madhya Pradesh & 11 & 8 & 11 & 13 & 9 & 13 & 12 & 11 & 14 & 9 \\
\hline Maharashtra & 6 & 1 & 5 & 11 & 4 & 12 & 2 & 1 & 13 & 7 \\
\hline Orissa & 2 & 6 & 7 & 7 & 12 & 5 & 16 & 14 & 6 & 6 \\
\hline Punjab & 3 & 7 & 2 & 3 & 2 & 3 & 5 & 3 & 3 & 15 \\
\hline Rajasthan & 16 & 15 & 16 & 12 & 14 & 11 & 9 & 13 & 9 & 11 \\
\hline Tamil Nadu & 4 & 2 & 3 & 5 & 3 & 8 & 3 & 2 & 10 & 5 \\
\hline Uttar Pradesh & 15 & 16 & 15 & 10 & 15 & 7 & 8 & 12 & 16 & 13 \\
\hline West Bengal & 5 & 5 & 4 & 2 & 11 & 2 & 4 & 4 & 11 & 10 \\
\hline \multicolumn{11}{|l|}{ Rank correlation } \\
\hline$\%$ changes in $\mathrm{PC}$ & & 0.80 & 0.90 & 0.53 & 0.39 & 0.52 & 0.34 & 0.39 & 0.38 & 0.39 \\
\hline index, 1983-2004 & -- & $(.00)$ & $(.00)$ & $(.04)$ & (.13) & $(.04)$ & $(.20)$ & $(.13)$ & $(.14)$ & $(.14)$ \\
\hline$\%$ changes in $\mathrm{Ov}$ & 0.80 & & 0.81 & 0.49 & 0.49 & 0.34 & 0.46 & 0.53 & -0.05 & 0.54 \\
\hline index, 1983-2004 & $(.00)$ & -- & $(.00)$ & $(.05)$ & $(.05)$ & $(.19)$ & $(.07)$ & $(.03)$ & $(.85)$ & $(.03)$ \\
\hline$\%$ changes in GIO & 0.90 & 0.81 & & 0.64 & 0.57 & 0.50 & 0.56 & 0.59 & 0.26 & 0.51 \\
\hline index, 1983-2004 & $(.00)$ & $(.00)$ & -- & $(.01)$ & $(.02)$ & $(.05)$ & $(.03)$ & $(.02)$ & $(.34)$ & $(.04)$ \\
\hline
\end{tabular}

Note: (a) Figures of rankings of Growth Elasticities of Poverty, Growth Rates, and Policies of Indian States correspond to the period 1958-2000 and are obtained from Besley, Burgess and EsteveVolart (2007). "Voice and accountability" is measured by newspaper circulation per capita. (b) Rankings are based on the average variable of interest over the period $(1=$ highest). (c) Significant levels for correlations are in parentheses. (d) Ranks in terms of changes in inequality indices are used. *These ranks were re-converted according to the mid-rank method in order to estimate the rank correlations with the inequality indicators. 
Lastly, our preceding analysis was based on common types across states. In Appendix Table 6 we allow for states to differ in types' composition. Our major conclusions appear significantly robust to this alternative. Changes in inequality indices are almost always positively correlated with our policy indicators and these remain statistically significant in most cases. As before, educational expenditure stands out for its lack of correlation with changes in inequality.

To summarize, states with more accountable governments, greater access to finance, greater reduction in poverty, and greater inclusion of women in economic growth emerged as those that also succeeded in reducing inequality of opportunity. The positive correlations between policy variables, poverty reduction, growth elasticities of poverty, growth rates and inequality of opportunity are descriptive - they do not imply causality. ${ }^{27}$ Nonetheless, they help clarify the variables' overall effect on inequality of opportunity. The policies we have identified may be reducing inequality of opportunity because they positively affect growth and enhance the poverty effect of growth.

\section{Conclusion}

Our results show that India's record in reducing inequality of educational opportunity in postliberalization is characterized by considerable variation across states and regions. The state of Kerala stands out as the least unequal in terms of educational opportunities irrespective of the index used. In general, Southern states experienced lower inequality in educational opportunity when compared to Northern states. This finding is consistent with observed North-South divide in social outcomes in India - numerous earlier studies have pointed out how Southern states such as Kerala and Tamil Nadu differ from Uttar Pradesh and Bihar in education and health outcomes (Dyson and Moore, 1983; Dreze and Sen, 1995). In addition, even after excluding the single success story, Kerala, significant inter-state divergence remains amongst the remaining states. Our findings show that different kinds of problem arise in different parts of India. The incidence of rural poverty is high in the Eastern states of Bihar, Orissa, and West Bengal. Yet both West Bengal and Orissa made significant progress in reducing inequality of opportunity whilst the situation worsened in Bihar. On average, states with more accountable governments,

${ }^{27}$ For instance, there are well-known regional divides in norms and culture within India. For instance, in an insightful study, Jejeebhoy and Sathar (2001) compare the lives of women and explore dimensions of their autonomy in different regions of South Asia-Punjab in Pakistan, and Uttar Pradesh in north India and Tamil Nadu in south India. They find that while women's autonomy is constrained in all three settings, women in Tamil Nadu fare considerably better than other women, irrespective of religion. If true, the origin of cross-state differences in educational opportunities may lie in regional differences in norms and educational preferences within India, amongst other factors. 
greater access to finance, greater reduction in poverty, and greater inclusion of women in economic growth emerged as those that also succeeded in reducing inequality of educational opportunities. In other words, although not causal, significant positive associations were found between policy variables, poverty reduction, GDP growth elasticity of poverty, growth rates and reduction in inequality of educational opportunities. The policies we have identified may be reducing inequality of opportunity because they positively affect economic growth and enhance the poverty effect of such growth.

Because the study period provides with both pre- and post-reform data on India, it is tempting to attribute the rising inequality of opportunities in some states and in some measures of opportunity to market reforms. The last decade has been a period of unprecedented improvement in living standards, thanks to liberalisation. The accelerated progress of elementary education in the nineties in some states may have been a response to weakening of credit constraints and increasing market returns to education which followed economic reforms and liberalisation of 1990s. Therefore the finding of a positive correlation between reduction of inequality of educational opportunity and poverty reduction and growth is reassuring. If true, this suggests that social inequality does not matter as long as economic growth and poverty reduction is in place. However, as argued by Dreze and Deaton (2002), "Much else than liberalisation has happened in the nineties, and while issues of economic reform are of course extremely important, so are other aspects of economic and social policy".

Lastly, it will be interesting to follow up this study using more recent data in the near future. The last couple of years have seen marked improvement in school participation which is arguably due to the Sarva Shiksha Abhiyan (SSA) "education for all" initiative. SSA aimed at achieving five years of primary schooling for all children by 2007. Nonetheless, completion rates for grade 5 had only reached $70 \%$ by $2005-6$ with significant variations across states. Similarly, although the SSA scheme aimed at achieving eight years of schooling for children aged 14-17 years, only slightly more than $50 \%$ of all 15 -year-olds had completed eight years of schooling in 2004 . Even then, considerable cross-state differences remained (Dougherty and Herd, 2008). Moreover, attention needs to be given to circumstance factors such as childhood poverty that affect schooling directly and are common across some social groups. 


\section{References}

Asadullah, M Niaz, Kambhampati, Uma. and Lopez-Boo, Florencia (2009) "Social divisions in school participation and attainment in India: 1983-2004”, IDB working paper no 692.

Alexander, John M. (2003) "Inequality, Poverty and Affirmative Action: Contemporary Trends in India', Mimeograph", Paper presented at the WIDER conference Inequality, Poverty and Human Well-being, 30-31 May 2003, United Nations University, Helsinki, Finland.

Behrman, Jere, Birdsall, Nancy and Miguel Székely (2001) "Intergenerational Mobility in Latin America," RES Working Papers 4267, Inter-American Development Bank, Research

Behrman, Jere R., Nancy Birdsall and Miguel Székely (1998) "Intergenerational Schooling Mobility and Macro Conditions and Schooling Policies in Latin America," Washington D.C., Inter-American Development Bank Office of the Chief Economist Working Paper \#386.

Besley, Tim, and Robin Burgess (2000) "Land reform, poverty, and growth: Evidence from India", Quarterly Journal of Economics,115(2): 389-430.

Besley, Tim, Robin Burgess and Berta Esteve-Volart (2007) "The Policy Origins of Poverty and Growth in India", in Delivering on the Promise of Pro-Poor Growth, edited by Tim Besley and Louise Cord (London: Palgrave Macmillan and the World Bank).

Checchi, Daniele and Vito Peragine (2005) "Regional disparities and inequality of opportunity: the case of Italy", Discussion Paper Series, 1874, IZA.

Cramer, H. (1946), Mathematical methods for Statistics, Princeton: Princeton University Press.

Deaton, A. and Dreze, J. (2002) "Poverty and Inequality in India: a Re-examination", Economic and Political Weekly, September 7, 2002, pp. 3729-3748.

Dahan, Momi and Gaviria, Alejandro (2001) "Sibling Correlations and Intergenerational Mobility in Latin America," Economic Development and Cultural Change, vol. 49(3), pages 537-54.

Desai, Sonalde and Kulkarni, Veena (2008) "Changing Educational Inequalities in India in the Context of Affirmative Action” Demography; 45(2): 245-270.

Deshpande, Ashwini (2007) "Overlapping Identities under Liberalization: Gender and Caste in India," Economic Development and Cultural Change, vol. 55, pages 735-760.

Dreze, Jean and Amartya Sen (1995) India: Economic Development and Social Opportunity. Delhi: Oxford University Press.

Dougherty, S. and R. Herd (2008) "Improving Human Capital Formation in India", OECD Economics Department Working Papers, No. 625. doi:10.1787/241005853765

Elbers, Chris, Peter Lanjouw, Johan Mistiaen and Berk Ozler (2008) "Reinterpreting betweengroup inequality", Journal of Economic Inequality, 6(3): 231-45.

Ferreira, Francisco and Jeremie Gignoux (2008) "The measurement of inequality of opportunity: theory and application to Latin America", mimeograph.

Foster, James and Artyom Shneyerov (2000) "Path independent inequality measures", Joumal of Economic Theory, 91(2): 1999-222.

Friedman, Milton (1937) "The use of ranks to avoid the assumption of normality implicit in the analysis of variance", Journal of the American Statistical Association 32: 675-701.

Hogg, Robert and Elliot Tanis (1997) Probability and statistical inference, New Jersey: Prentice Hall.

Jejeebhoy, S. J. and Z. Sathar (2001) "Women's Autonomy in India and Pakistan: The Influence of Religion and Region", Population and Development Review 27 (4):687-712.

Kendall, Maurice and Alan, Stuart (1973), The Advanced Theory of Statistics, Vol. 2, London: Griffin, $3^{\text {rd }}$ Edition.

Kingdon, Geeta (2007) “The progress of school education in India”, Oxford Review of Economic Policy, vol. 23(2), pages 168-195.

Lefranc, Arnaud, Nicolas Pistolesi and Alain Trannoy (2008) "Inequality of opportunities vs. inequality of outcomes: are Western societies all alike?", The Review of Income and Wealth, 54(4): 513-46. 
Lanjouw, Peter and Rinku Murgai (2009) "Poverty decline, agricultural wages, and nonfarm employment in rural India: 1983-2004”, Agricultural Economics, vol. 40(2), pages 243-263.

Roemer, John (1998) Equality of Opportunities. Cambridge: Harvard University Press.

Schütz, Gabriela \& Heinrich W. Ursprung \& Ludger Wößmann (2008) "Education Policy and Equality of Opportunity," Ky/klos, vol. 61(2), pages 279-308, 05.

Sen, Amartya (1976) "Real national income", Review of Economic studies, 43(1): 19-39.

Sen, Amartya (2001) Development as Freedom, Oxford: Oxford University Press.

Sachar, R. (2006) Social, Economic and Educational Status of the Muslim Community of India: A Report. New Delhi, India: Prime Minister's High Level Committee Cabinet Secretariat Government of India.

Thomas, Vinod, Wang, Yanling and Fan, Xibo (2000) "Measuring Education Inequality: Gini Coefficients of Education", World Bank Working paper no 2525.

Weitzman, Murray (1970) "Measures of overlap of income distributions of white and negro families in the U.S.", Tech. Paper 22, Bureau of the Census.

Wu, Kin Bing, Pete Goldschmidt, Mehtabul Azam and Christy Kim Boscardin (2006) "Girls in India: Poverty, Location, and Social Disparities", in M. Lewis and M. Lockheed (eds.), Exclusion, Gender and Education: Case Studies from the Developing World, Center for Global Development, Washington, DC.

Yalonetzky, Gaston (2009a) "A dissimilarity index of multidimensional inequality of opportunity”, OPHI Working Paper 28.

Yalonetzky, Gaston (2009b) "Comparing economic mobility with a dissimilarity index: an application to education in Peru", OPHI Working paper 31.

Yalonetzky, Gaston (2010) "A comparison between the Pearson-based dissimilarity index and the multivariate overlap index", forthcoming OPHI Working Paper. 
Appendix Figure 1: PC index and GIO index. India, 1983-2004

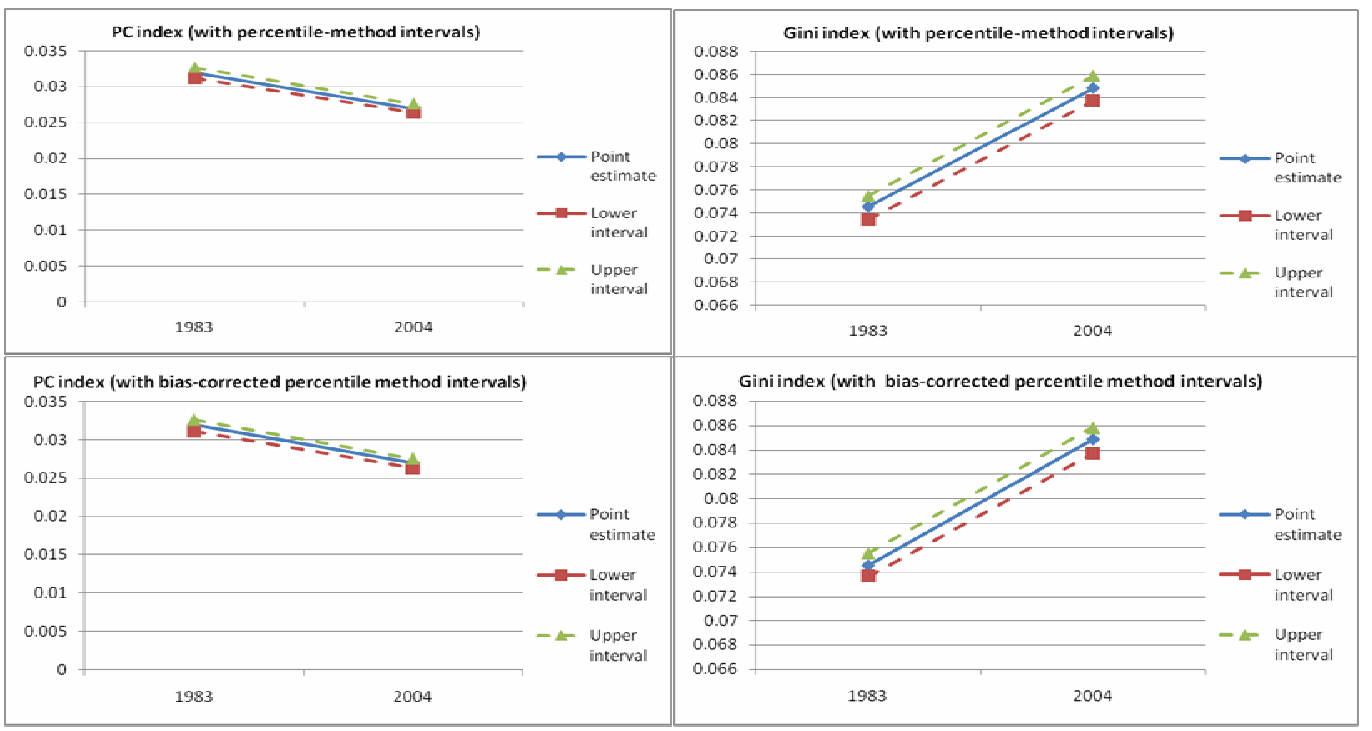

Notes: (a) Confidence intervals are at 95\% level and obtained following the bootstrapping percentile method. (b) The bottom panel report bootstrapped, bias-corrected CIs. (c) For each sample 1,000 re-samplings were conducted.

Appendix Figure 2: Changes in inequality of opportunity in education according to the PC index and GIO index across Indian regions
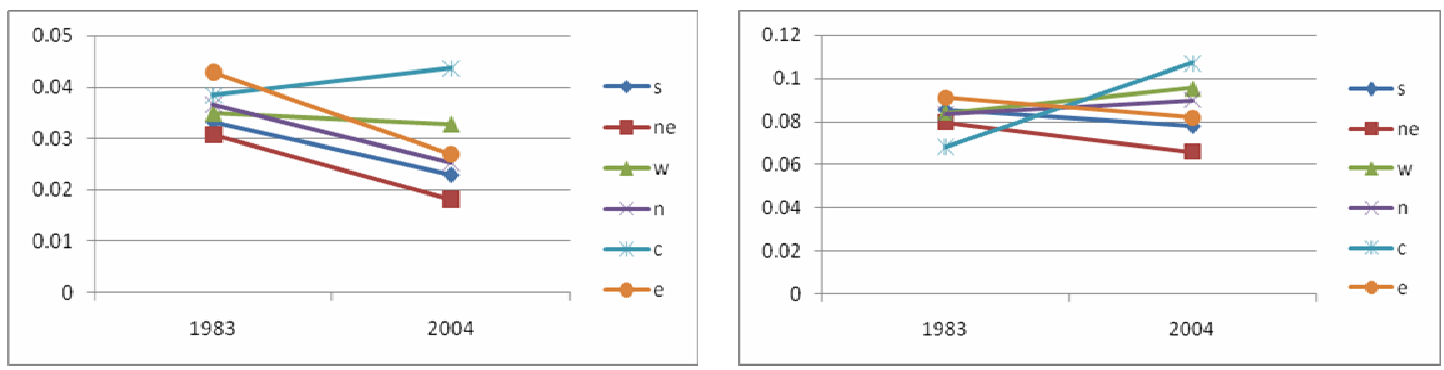

Notes: Estimates based on data on adults aged 25 years and older. 
Appendix Table 1: Transition matrix of PC index (state-level aggregate data)

\begin{tabular}{|c|c|c|c|c|c|c|}
\hline \multirow{6}{*}{$\begin{array}{l}\text { Quartile O } \\
\text { education } \\
\text { opportunity } \\
\text { inequality it } \\
1983\end{array}$} & \multirow{4}{*}{ I } & \multicolumn{4}{|c|}{ Quartile of education opportunity inequality in 2004} & \multirow{3}{*}{$\begin{array}{l}\text { Totals } \\
7\end{array}$} \\
\hline & & $\mathbf{I}$ & II & III & IV & \\
\hline & & 3 & 3 & 1 & 0 & \\
\hline & & & & & & 6 \\
\hline & & 0 & 1 & 2 & 3 & \\
\hline & III & 3 & 1 & 1 & 1 & 6 \\
\hline & IV & 0 & 1 & 2 & 3 & 6 \\
\hline & totals & 6 & 6 & 6 & 7 & 25 \\
\hline & $\begin{array}{l}\text { Trace index } \\
\text { Pearson chi-square }\end{array}$ & $\begin{array}{l}0.91 \\
12.20(0.20)\end{array}$ & & & & \\
\hline
\end{tabular}

Notes: (a) Estimates are based on 25 observations (state-level) per year. (b) Comparable circumstance sets are: Hindu male, Hindu female, non-Hindu male, non-Hindu female. (c) Data is restricted to adults aged 25 years old or above. (d) p-value in parenthesis.

Appendix Table 2: Transition matrix of PC index (state-level data across rural and urban areas)

\begin{tabular}{|c|c|c|c|c|c|c|}
\hline \multirow{5}{*}{$\begin{array}{l}\text { Quartile of } \\
\text { education } \\
\text { opportunity } \\
\text { inequality in } \\
1983\end{array}$} & \multirow[b]{3}{*}{$\mathbf{I}$} & \multicolumn{4}{|c|}{ Quartile of education opportunity inequality in 2004} & \multirow{3}{*}{$\begin{array}{l}\text { Totals } \\
12\end{array}$} \\
\hline & & I & II & III & IV & \\
\hline & & 6 & 4 & 2 & 0 & \\
\hline & II & 5 & 2 & 2 & 2 & 11 \\
\hline & III & 1 & 2 & 3 & 5 & 11 \\
\hline \multirow{4}{*}{ Summary stat } & IV & 0 & 2 & 4 & 5 & 11 \\
\hline & totals & 12 & 10 & 11 & 12 & \multirow[t]{3}{*}{45} \\
\hline & Trace index & \multirow{2}{*}{\multicolumn{4}{|c|}{$\begin{array}{l}0.86 \\
16.58(0.05)\end{array}$}} & \\
\hline & Pearson chi-square & & & & & \\
\hline
\end{tabular}

Notes: (a) Estimates are based on 45 observations per year. (b) Comparable circumstance sets are: Hindu male, Hindu female, non-Hindu male, non-Hindu female. (c) Data is restricted to adults aged 25 years old or above. (d) p-value in parenthesis. 
Appendix Table 3: Estimates of Inequality of educational opportunity indices by region and year

\begin{tabular}{|c|c|c|c|c|c|c|c|c|}
\hline \multirow[b]{3}{*}{ Regions } & \multicolumn{4}{|l|}{1983} & \multicolumn{4}{|l|}{2004} \\
\hline & \multicolumn{2}{|l|}{ Ranks } & \multicolumn{2}{|l|}{ Means } & \multicolumn{2}{|l|}{ Ranks } & \multicolumn{2}{|l|}{ Means } \\
\hline & PC index & $\begin{array}{l}\text { Gini } \\
\text { index }\end{array}$ & $\begin{array}{l}\% \% \text { of } \\
\text { population } \\
\text { with } \\
\text { secondary+ } \\
\text { education }\end{array}$ & $\begin{array}{l}\% \text { of } \\
\text { population } \\
\text { with } \\
\text { primary+ } \\
\text { education }\end{array}$ & PC index & $\begin{array}{l}\text { Gini } \\
\text { index }\end{array}$ & $\begin{array}{l}\% \% \text { of } \\
\text { population } \\
\text { with } \\
\text { secondary+ } \\
\text { education }\end{array}$ & $\begin{array}{l}\% \% \text { of } \\
\text { population } \\
\text { with } \\
\text { primary+ } \\
\text { education }\end{array}$ \\
\hline South & 5 & 2 & 0.11 & 0.36 & 5 & 5 & 0.24 & 0.54 \\
\hline North-East & 6 & 5 & 0.10 & 0.38 & 6 & 6 & 0.24 & 0.59 \\
\hline West & 4 & 3 & 0.13 & 0.33 & 2 & 2 & 0.26 & 0.53 \\
\hline North & 3 & 4 & 0.12 & 0.28 & 4 & 3 & 0.29 & 0.54 \\
\hline Central & 2 & 6 & 0.09 & 0.23 & 1 & 1 & 0.23 & 0.44 \\
\hline East & 1 & 1 & 0.12 & 0.35 & 3 & 4 & 0.20 & 0.49 \\
\hline Rank correlations & 0.2 & & & & 0.94 & & & \\
\hline
\end{tabular}

Notes: (a) Figures on indices are ranks. (b) Ranks: 1=most unequal. (c) South: Andhra Pradesh, Karnataka, Kerala, Tamil Nadu, Pondicherry; North-East: Assam, Manipur, Meghalaya, Mizoram, Nagaland, Sikkim, Tripura, Arunachal Pradesh; West: Gujarat, Maharashtra, Rajasthan, Dadra and Nagar Haveli, Goa; North: Himachal Pradesh, Jammu and Kashmir, Punjab, Chandigarh; Central: Bihar, Haryana, Madhya Pradesh, Uttar Pradesh, Delhi; East: Orissa, West Bengal.

Appendix Table 4: Transition matrix of PC index (region-level data across rural and urban areas)

\begin{tabular}{|c|c|c|c|c|c|}
\hline \multirow{5}{*}{$\begin{array}{l}\text { Quartile of } \\
\text { education } \\
\text { opportunity } \\
\text { inequality in } \\
1983\end{array}$} & \multirow[b]{3}{*}{ I } & \multicolumn{3}{|c|}{$\begin{array}{l}\text { Quartile of education opportunity inequality in } \\
2004\end{array}$} & \multirow{3}{*}{$\begin{array}{l}\text { totals } \\
4\end{array}$} \\
\hline & & $\mathrm{I}$ & II & III & \\
\hline & & 1 & 3 & 0 & \\
\hline & II & 2 & 1 & 1 & 4 \\
\hline & III & 1 & 0 & 3 & 4 \\
\hline \multirow{3}{*}{ Summary stat } & totals & 4 & 4 & 4 & \multirow[t]{3}{*}{12} \\
\hline & Trace index & \multirow{2}{*}{\multicolumn{3}{|c|}{$\begin{array}{l}0.87 \\
7.5(0.11)\end{array}$}} & \\
\hline & Pearson chi-square & & & & \\
\hline
\end{tabular}

Notes: (a) Estimates are based on 12 observations (2 observations per region) per year. (b) Comparable circumstance sets are: Hindu male, Hindu female, non-Hindu male, non-Hindu female. (c) Data is restricted to adults aged 25 years old or above. (d) p-value in parenthesis. 
Appendix Table 5: Estimates of Inequality of educational opportunity indices by state and year (different types) ${ }^{28}$

\begin{tabular}{|c|c|c|c|c|c|c|c|c|c|c|}
\hline \multirow{4}{*}{$\begin{array}{l}\text { Rank correlations } \\
\text { PC index }\end{array}$} & \multicolumn{5}{|c|}{1983} & \multicolumn{5}{|c|}{2004} \\
\hline & \multicolumn{3}{|c|}{ Inequality of opportunity index } & \multirow[t]{2}{*}{$\begin{array}{l}\% \text { of population } \\
\text { with secondary+ } \\
\text { education }\end{array}$} & \multirow[t]{2}{*}{$\begin{array}{l}\% \text { of population } \\
\text { with primary+ } \\
\text { education }\end{array}$} & \multicolumn{3}{|c|}{ Inequality of opportunity index } & \multirow[t]{2}{*}{$\begin{array}{l}\% \text { of population } \\
\text { with secondary+ } \\
\text { education }\end{array}$} & \multirow[t]{2}{*}{$\begin{array}{l}\% \text { of population } \\
\text { with primary+ } \\
\text { education }\end{array}$} \\
\hline & $\mathrm{PC}$ & Overlap & GIO & & & $\mathrm{PC}$ & Overlap & GIO & & \\
\hline & -- & $\begin{array}{l}0.08 \\
(.71) \\
\end{array}$ & $\begin{array}{l}0.35 \\
(.10) \\
\end{array}$ & $\begin{array}{l}0.38 \\
(.07) \\
\end{array}$ & $\begin{array}{l}0.31 \\
(.15) \\
\end{array}$ & -- & $\begin{array}{l}0.36 \\
(.09) \\
\end{array}$ & $\begin{array}{l}0.68 \\
(.00) \\
\end{array}$ & $\begin{array}{l}0.10 \\
(.65) \\
\end{array}$ & $\begin{array}{l}0.10 \\
(.64) \\
\end{array}$ \\
\hline Overlap index & $\begin{array}{l}0.08 \\
(.71) \\
\end{array}$ & -- & $\begin{array}{l}0.62 \\
(.00) \\
\end{array}$ & $\begin{array}{l}0.09 \\
(.68) \\
\end{array}$ & $\begin{array}{l}0.11 \\
(.60) \\
\end{array}$ & $\begin{array}{l}0.36 \\
(.09) \\
\end{array}$ & -- & $\begin{array}{l}0.78 \\
(.00) \\
\end{array}$ & $\begin{array}{l}0.16 \\
(.45) \\
\end{array}$ & $\begin{array}{l}0.17 \\
(.43) \\
\end{array}$ \\
\hline GIO index & $\begin{array}{l}0.35 \\
(.10) \\
\end{array}$ & $\begin{array}{l}0.62 \\
(.00) \\
\end{array}$ & -- & $\begin{array}{l}0.04 \\
(.85) \\
\end{array}$ & $\begin{array}{l}-0.04 \\
(.85) \\
\end{array}$ & $\begin{array}{l}0.68 \\
(.00)\end{array}$ & $\begin{array}{l}0.78 \\
(.00) \\
\end{array}$ & -- & $\begin{array}{l}0.19 \\
(.39) \\
\end{array}$ & $\begin{array}{l}0.24 \\
(.26) \\
\end{array}$ \\
\hline
\end{tabular}

Notes: (a) Ranks: $1=$ most unequal; $25=$ least unequal. (b) p-values in parenthesis.

Appendix Table 6: Inequality of opportunity rankings vis-à-vis growth, poverty and policies of Indian states (different types)

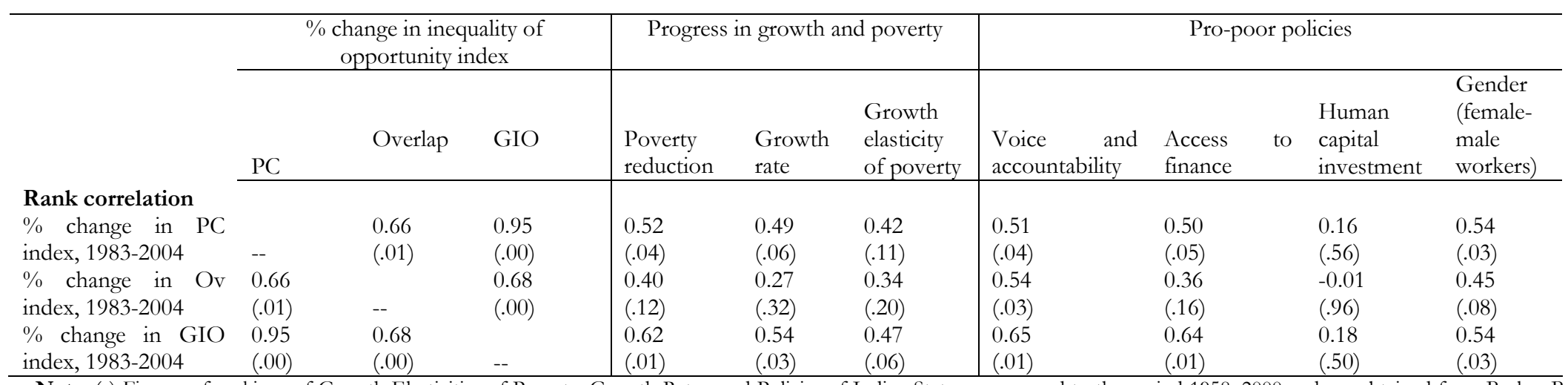

Note: (a) Figures of rankings of Growth Elasticities of Poverty, Growth Rates, and Policies of Indian States correspond to the period 1958-2000 and are obtained from Besley, Burgess and Esteve-

Volart (2007). "Voice and accountability" is measured by newspaper circulation per capita. (b) Rankings are based on the average variable of interest over the period ( 1 = highest). (c) Significant levels for correlations are in parentheses. (d) Ranks in terms of changes in inequality indices are used. *These ranks were re-converted according to the mid-rank method in order to estimate the rank correlations with the inequality indicators.

28 The Friedman test statistic is 37.36 for 1983 and 48.71 for 2004 . With one degree of freedom the null hypothesis of independence of the three indices' rankings is rejected at $99 \%$. 